This is a post-peer-review, pre-copyedit version of an article published in Personal and Ubiquitous Computing. The final authenticated version is available online at: https://doi.org/10.1007/s00779-018-1187-5

This version is subjected to Springer Nature terms for reuse that can be found at: https://www.springer.com/gp/open-access/authorsrights/aam-terms-v1 


\title{
Estimating Pro-Environmental Potential for the Development of Mobility-based Informational Intervention: A Data-Driven Algorithm
}

\author{
Shiraz Ahmed ${ }^{\mathrm{a}}$, Muhammad Adnan ${ }^{\mathrm{a}^{*}}$, Davy Janssens ${ }^{\mathrm{a}}$, Erika Brattich ${ }^{\mathrm{b}}$, Ansar-ul-Haque \\ Yasar $^{\mathrm{a}}$, Prashant Kumar ${ }^{\mathrm{c}}$, Silvana di Sabatino ${ }^{\mathrm{b}}$, Elhadi M. Shakshuki ${ }^{\mathrm{d}}$ \\ ${ }^{a}$ UHasselt - Hasselt University, Transportation Research Institute (IMOB), Agoralaan, 3590 Diepenbeek, Belgium \\ ${ }^{b}$ Department of Physics and Astronomy, Alma Mater Studiorum, University of Bologna, Bologna, Italy \\ ${ }^{c}$ Global Centre for Clean Air Research (GCARE), Department of Civil and Environmental Engineering, Faculty of Engineering and Physical \\ Sciences, University of Surrey, Guildford GU2 7XH, Surrey, United Kingdom \\ ${ }^{d}$ Jodrey School of Computer Science, Acadia University, Wolfville, Nova Scotia, Canada
}

\begin{abstract}
Informational interventions are important to bring positive changes in attitudes and perception among individuals. In relation to the individual's mobility behavior, habits, attitudes and perceptions are difficult to change. Therefore, it is vital to identify relatively soft aspects of travel behavior with a potential to reduce the negative impacts of mobility on the environment and individual health. This paper provides a methodological framework and describes the development of a computational algorithm that helps to identify soft changes in the travel behavior. The algorithm is based on a variety of different data sources such as activity-travel diaries and related constraint information, meteorological conditions, bicycle and public transport supply data, emissions and air pollutant concentrations data. A variety of rules that are part of the algorithm are derived from the transport modelling literature, where constraints and factors were examined for activity-travel decisions. Three major aspects of activity-travel behavior, such as reduced car use, cold start of car engines and participation in non-mandatory outdoor activities are considered in assessing pro-environmental potential. The algorithm is applied to collected small datasets from citizens of Hasselt (Belgium), Bologna (Italy) and Guildford (UK). A significant replaceable potential for car trips within $3 \mathrm{~km}$ to cycling and car trips to public transport has been found. The replaceable potential of excessive cold starts and participation in non-mandatory outdoor activities were also found, to some extent, to bring positive changes in the environment. In future research, these identified potentials are reported back to individuals with their consequence as part of a mobilitybased informational intervention.
\end{abstract}

Keywords: Pro-environmantal potential, acitivity-travel behavior, informational intervention, computational algorithm

\section{Introduction}

Many environmental problems such as urban air quality, global warming, environmental noise and continuous scarcity of resources (like water) are linked with the human behavior. The transport sector has contributed around $23 \%$ of the total $\mathrm{CO}_{2}$ emissions, which is the $2^{\text {nd }}$ highest in Europe [1]. Additionally, around 40 million people in the 115 largest cities in the European Union (EU) are exposed to at least one pollutant whose concentration values exceed WHO air quality guidelines [1]. Previous studies indicated that a variety of structural and informational interventions may change/manage human behavior to reduce the negative impacts of environmental problems. For example, Steg and Vlek [2] defined informational strategies as an approach to change perceptions, motivations, knowledge and norms, without disturbing the external context in which decisions are made. Strategies based on the information campaigns, social support and role models to influence the behavior of individuals can be categorized within this type of intervention approach. In order to obtain optimal results, it is recommended to combine informational strategies

\footnotetext{
* Corresponding Author, Tel.: +32-11-269-147 ; Fax: +32-11-269-199 ; E-mail address: muhammad.adnan@uhasselt.be
} 
with structural strategies (such as congestion charging, fare reduction, increased parking pricing, low emission zones etc.) [3].

Despite their advantages, informational based strategies/interventions in relation to personal mobility aspects are scarce in the literature. Schultz [4] mentioned that these interventions have the ability to promote pro-environmental aspects of an individual's behavior which are relatively easier and have high benefits. Based on the findings of Schultz [4], effective informational based intervention can be designed focusing on soft/easy aspects of individual's activitytravel behavior such as reduced travel for non-mandatory outdoor activities, use of bicycle/walk for short trips, use of public transport where overall travel time does not have significant differences from other efficient travel modes etc. In literature, these are considered as pro-environmental travel choices, as they bring not only improvement in air quality but also positive changes to an individual's health [5]. So, the vital step involved in the designing of mobilitybased informational intervention is to detect easy to replace activities and trips in an individual daily routine. This paper presents the development of an algorithm to identify those aspects of an individual activity-travel behavior that are flexible and not strictly constrained by time pressure, family engagement and other constraints. These relatively soft activity-travel choices can be replaced by more pro-environmental activity-travel choices, and therefore, the developed algorithm provides an assessment of a pro-environmental potential within an individual activity-travel routine. According to our knowledge, this is the first study that measured such potential in a comprehensive manner (i.e. by considering various constraints), even though the extent of car-based short trips in individuals travel patterns and their potential to reduce environmental impacts have been studied [6,7]. The developed algorithm presented in this paper is part of a development process of an informational intervention (designed based on inputs from several studies $[3,4,8]$ ), where individuals are provided information regarding the consequences of their activity-travel routine in three different aspects. These are as follows:

1) Customized information about their exposure to air pollutants based on recording their detailed activity-travel routine

2) Customized information about their contribution in GHG emission (based on their car use)

3) Customized information about their extent of contribution in physical activity (based on walking and bicycle use).

The intervention also provides individuals with suggestions about possible changes in their travel behavior (which is based on the developed algorithm as presented in the last part of the paper) and how these changes can reduce the impacts of the three consequences defined above. Therefore, the developed algorithm that helps identify proenvironmental potential within activity-travel routine of an individual is a key component for the assessment of the overall effectiveness of the intervention. It is important to note that this paper provides only the overview related to the development process of information intervention; however, it emphasizes more on the details of the data-driven based computational algorithm.

The remaining portion of the paper is arranged in the following sections. In Section 2, we give a brief overview of the methodological framework followed to develop such an algorithm. In section 3, we illustrate the algorithm in detail. Section 4 provides the demonstration of the algorithm based on the case studies conducted using small datasets collected from citizens of Hasselt city (Belgium), Bologna (Italy) and Guildford (UK). Section 5 finally provides the conclusion and next steps of the research.

\section{Related Existing Work}

A continuous increase in the personal motorized vehicles moving on the roads has become a significant threat for our healthy living concerning an increase in air pollution and climate change. From the last two decades the transportation and environment experts have been working on these topics and proposed/implemented various strategies to mitigate this problem. In this context, a variety of transport related initiatives are taken to influence travel behavior by discouraging individual car use and encouraging environment friendly mobility options (such as increased use of public transport and active travel modes) through interventions/strategies [9]. These initiatives can be classified as informational and structural interventions. Structural strategies have a push effect including: public transport infrastructure improvement, increased parking prices, introduction of low emission zones, etc [10]. These measures are difficult to implement due to the involvement of high capital cost, public defiance and political pressure[11]. Information strategies have pull effect and have ability to influence the socio-cognitive aspects of travel behavior of 
individuals using techniques of information dissemination and persuasion. In some situations, information strategies are also effective to bring the required results [11] . Information strategies include awareness campaigns, personalized travel coaching, social marketing of public transport, seminar highlighting health benefits of active travelling and use of role models to voluntarily shift to the pro-environmental travel behavior [10-14].

In different regions of the world, programs to change travel behavior were implemented with the common intention of motivating people to decrease car use [15]. Typical strategies or measures adopted in these programs are based on actions that include providing better information on travel choices, personalized assistance, and motivation or incentives. The key characteristic of these strategies are that they can possibly give cost effective solution by shifting car to public and active (walking and cycling) modes of travel [16]. Indimark is one of the programs that has been successfully implemented in 12 European countries and Australia. It offers personalized promotion of public transportation, cycling and walking to individuals by providing customized information that includes guides to walking and cycling in the locality, schedules and maps for public transport routes, consistent with individual requirements [17]. Another popular awareness campaign, Travel Blending, has been applied in Australia, UK, USA and Chile with the aim to decrease car use by blending/mixing of travel choices over time at the individual level. It elevates individuals' awareness about the possible consequences of their car use by giving feedback based on the travel diaries filled by them for one week. Feedback report provides tailored information about the car use in terms of total kilometers travelled along with cold starts and emissions produced with suggestions such as replace car trip with public transport one day a week or one day a fortnight [18]. Crains et al, reviewed various nationwide programs implemented in UK to encourage sustainable modes of travel and concluded that such measures could play a very substantial role to reduce traffic levels especially at peak hours [19]. Fujii and Taniguchi found that in general soft transport strategies are effective and resulted in significant decrease in car use and greenhouse gas emissions [20].

Keeping in view the current situation, interventions focusing on encouraging individuals to adopt sustainable ways of travelling will, therefore, remain the main element of every car use reduction strategy in the future. Further intervention should be designed targeting easy to change behavior such as short car trips within three kilometers keeping in view certain constraints such as time pressure, family engagement etc. In this context, handful studies aimed to detect replaceable car trip potential with their possible impacts on the environment were previously conducted. In one such study using NPTS95 (1995 US Nationwide Personal Transportation Survey) data, an effort was made to detect the replaceable potential of short trips within three kilometers by considering personal, household and situational factors. Based on the replaceable potential, reduction in emissions was found to be 70 tons of VOCs, 900 tons of CO and 35 tons of NOx per day across the US [6]. In this study, manually filled one-day travel diary, i.e. not truly representative of the actual travel behavior because of the tendency of individuals to forget reporting of short trips and activities, was used. This has been the finding of several studies in which comparison is made about the selfreported data and recorded activity patterns using GPS-based tools [21]. Furthermore, assessment of the replaceable potential has been done without considering the built environment constraints such as availability of bicycle and walking paths with associated parameters such as segregated lanes, gradients, crossings etc. Kim et al [7] tried to identify factors affecting the mode choice of home-based short trips based on personal, household, trip, and neighborhood characteristics with the intention to reduce car use. In this study, the limited two-day data from 1999 Household Activity Travel Survey Data of Central Puget Sound region, including only home-based trips with single mode and activity avoiding complex trip activity patterns, was used . This type of approaches gives information about specific scenarios rather than giving complete insights associated with an individual activity-travel behavior.

In another study, based on the on-board data logging devices in cars of 20 individuals in Flanders region (Belgium), it is observed that only 9.5 percent of home-based car trips are potentially replaceable by cycling. The study used the criteria for selecting the replaceable car trips as; trips having a maximum distance of $8 \mathrm{~km}$, without any passenger, and excluding shopping trips. The stringent criteria are adopted by excluding all the daily grocery trips and considered them as trips with the heavy goods that seems irrational. Furthermore, constraints such as cycling infrastructure facilities, terrain nature and weather conditions, which can help determine replaceable potential in a more appropriate manner [22], were not considered. The study conducted in Perth (Australia) [23] found that 50 percent of all car trips were in principle replaceable considering individual's subjective and objective constraints. This is $35 \%$ percent points 
lesser if this potential is measured without these constraints. Car trips performed for business reasons, transport of heavy luggage and non-availability of public transport were considered constraints in this study. This approach to an extent can provide realistic replaceable potential at an individual level, even though other constraints need to be considered.

This study is motivated by the need to improve the way of determining the replaceable potential within an individual activity-travel behavior that helps to adopt environmental friendly mobility routine. Based on the shortcomings observed in the past studies, a holistic framework is devised for the development of a computational algorithm that detects the pro-environmental potential in an activity travel routine of an individual taking into account the personal, household, metrological and infrastructural constraints. The computational algorithm also has an ability to determine the consequences in terms of GHG emissions and physical activity associated with an individual's current and suggested travel behavior based on the replaceable potential. The details regarding primary data acquisition i.e activity travel diary with data sets required for the potential determination is mentioned in the section "Methodological Framework".

\section{Methodological Framework}

This section provides details of the steps taken in order to develop an algorithm. There were two major steps in the process, which are as follows: 1) Pro-environmental travel behavior - definition and concepts, and 2) Formulating data requirements and their acquisition methods. More details of each step are provided in the following sub-sections.

\subsection{Pro-environmental Travel Behavior - Definition and Concepts}

Individual travel behavior is depicted from the travel choices one makes to perform daily activities and the environmental impact of personal mobility is assessed by quantifying its harmful effects on the surroundings and society. A more pro-environmental activity travel behavior is identified as having less environmental impact, for example traveling shorter distances to perform a particular activity by using public transport, cycling/walking instead of using the car. So, depending upon the impact on the environment, travel behavior can be expressed as more or less pro-environmental. In the past, studies were conducted with the aim to determine various environmental friendly mobility behaviors with a potential to improve air quality and reduce GHG emissions: for example, reduced car use, avoiding unnecessary cold start of vehicle engine and use of active travel mode (such as walk, bicycle and public transport) $[24,25]$. Andrey et al [6] found that replacing the car short trips with active modes resulted in daily savings in emissions of approximately 46,000 tons of $\mathrm{CO}_{2}$ equivalent in US. In another study 30-50 percent reduction in emissions was observed in the hot start as compared to the cold start of four cylinder direct injection diesel engine [26].

Further, in order to motivate individuals regarding pro-environmental travel behavior, it is also important to investigate thoroughly constraints and factors on which individual activity-travel decisions are based: for instance, cycling and walking cannot be a preferred mode in extreme weather conditions (i.e. during severe cold and heavy rain), while public transport can be preferred when the generalized cost of waiting time, number of transfers, fare, access and egress walk is significantly lower in relation to generalized cost of using a car or taxi. Therefore, it is of paramount importance to understand correctly also the context within which individuals are making their travel decisions. These factors and constraints were examined well in the travel behavior literature [27]. To develop our algorithm, we have identified several factors and constraints in relation to complex activity-travel routine of individuals on a particular day. We present here the factors/constraints that we adopted for bicycle use [28,29]: travel distance (lesser is better), terrain (flat terrain increase the propensity to bicycling), segregated bike paths (more is better), temperature (range between $5-20^{\circ} \mathrm{C}$ is found to be more suitable), rain (bicycling is not preferred when there is a heavy shower), age (not preferred for individuals higher than 60 years or lesser than 12 years), not preferred when trip involves carrying a large quantity of goods/groceries, preferred when travel needs to be performed alone. Higher wind can also deter choice of cycling, however, it mostly depends on geography of the region, time of study and also climatic conditions of the region. 


\subsection{Formulating Data Requirement and Acquisition Methodology}

An algorithm which can identify pro-environmental potential requires a variety of datasets. On one hand, it requires data from the individuals activity-travel routine (in the form of daily diaries), and on the other hand, it requires information about activity purpose and flexibility, presence and characteristics of the accompanying persons and transport of a large quantity of goods etc. Additionally, it also requires other third-party datasets such as information about meteorological conditions (temperature and rain etc.), availability of public transport routes (their frequency, access and egress walking time) and bicycle paths etc. Therefore, acquisition and handling of such a variety of dataset require careful development of database and protocols under which these datasets are integrated to each other. In the following, we report a summary of acquisition of these datasets.

Activity-travel diary information of an individual is collected via a GPS based smartphone application, SPARROWS, that has been developed by Transportation Research Institute (IMOB) at Hasselt University. The main idea of using the GPS based application was to avoid any misspecification of activity location data and missing information of short trips. which is often forgotten by individuals when they are filling their previous day activitytravel routine in some other survey instruments. The smartphone app works in conjunction with a prompted recall web-survey, which, based on the processing of GPS traces obtained from an individual's smartphone in the form of stops and trips coupled with background google map environment, are provided to individuals for their detailed annotation. This acts as a memory prompt to the respondent thus allowing the individual to respond to the asked questions regarding stops and trips without any difficulties. Fig. 1. provides the methodological details of the instrument. The questions in the survey include: activity purpose for 10 different categories (including waiting at bus/train/tram station), flexibility of activity start and end time (in terms of yes/no), indoor/outdoor activity, travel modes, travelling with friends/family members (only adults or with kids as well), fuel type if car is used and information whether the trip involves carrying a large quantity of goods. For each episode that comprehends one trip with associated activity, the above-mentioned questions are asked as shown in Fig. 2 and 3. Further individual household details such as availability of bicycle, car details are taken in the form of responses received from the introductory questionnaire at the time of recruitment of individuals.

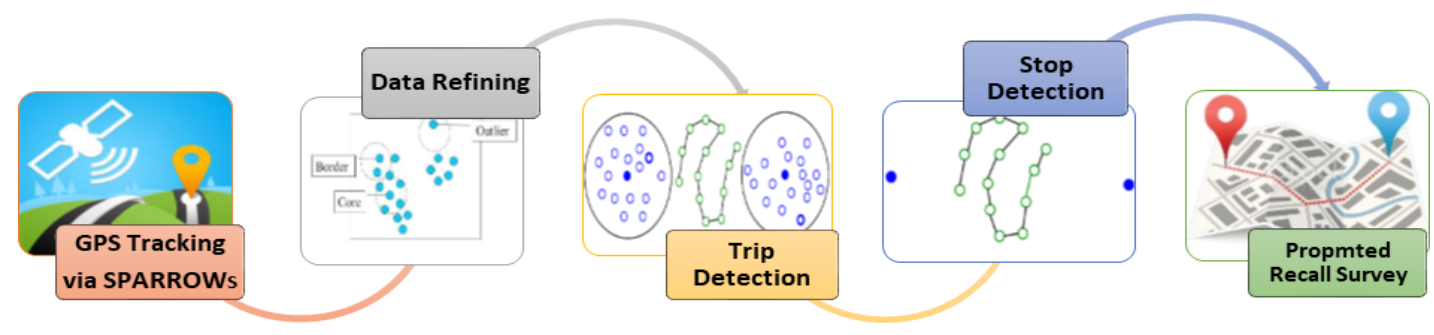

Fig. 1: Schematic Diagram representing the steps involved in activity-travel diary collection

The other $3^{\text {rd }}$ party data such as meteorological data in terms of temperature and precipitation data for dates when activity-travel routine of individuals are recorded can be easily obtained from online regional meteorological websites. This information can easily be integrated as an additional attribute with each outdoor activity and trip based on the recorded timestamp. In addition, public transport schedules, route information along with other relevant details, easily integrated with the road network data to identify a public transport route between an origin and destination along with other details such as travel time, waiting time, transfer and access/egress distances to assess the possibility and the reasonableness to replace a car trip, can be obtained from General transit feed specification . Considering that bicycling infrastructure information is also important for our study, it was acquired from available route planners website such as combining information from Google maps and Route-You (www.routeyou.com), where bicycle routes are classified in terms of recreational cycling routes and short routes with terrain information. Finally, in order to measure the consequences of the individual travel behavior with and without pro-environmental potentials, various datasets are required. For exposure estimation, hourly pollutant concentration maps of $\mathrm{O}_{3}, \mathrm{NO}_{2}$, and particulate matter in form of PM10 and PM2.5 were obtained at spatial resolution of $1 \mathrm{sq} . \mathrm{km}$. Details regarding the household and personal cars 
such as model name and manufacturing year was asked in the introductory questionnaire. Further emission factors and related details were gathered from the emission inventory datasets available for different regions [30,31].

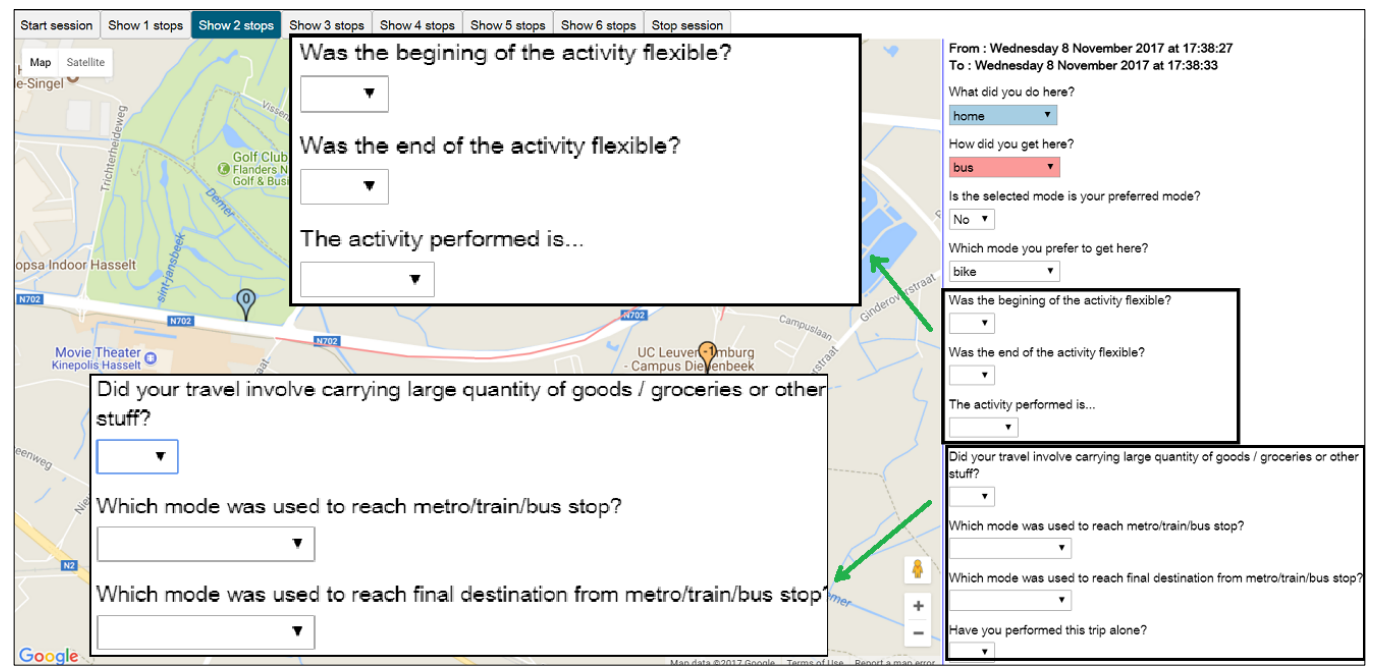

Fig. 2: SPARROWS window showing Questions related to Trip and Activity attributes

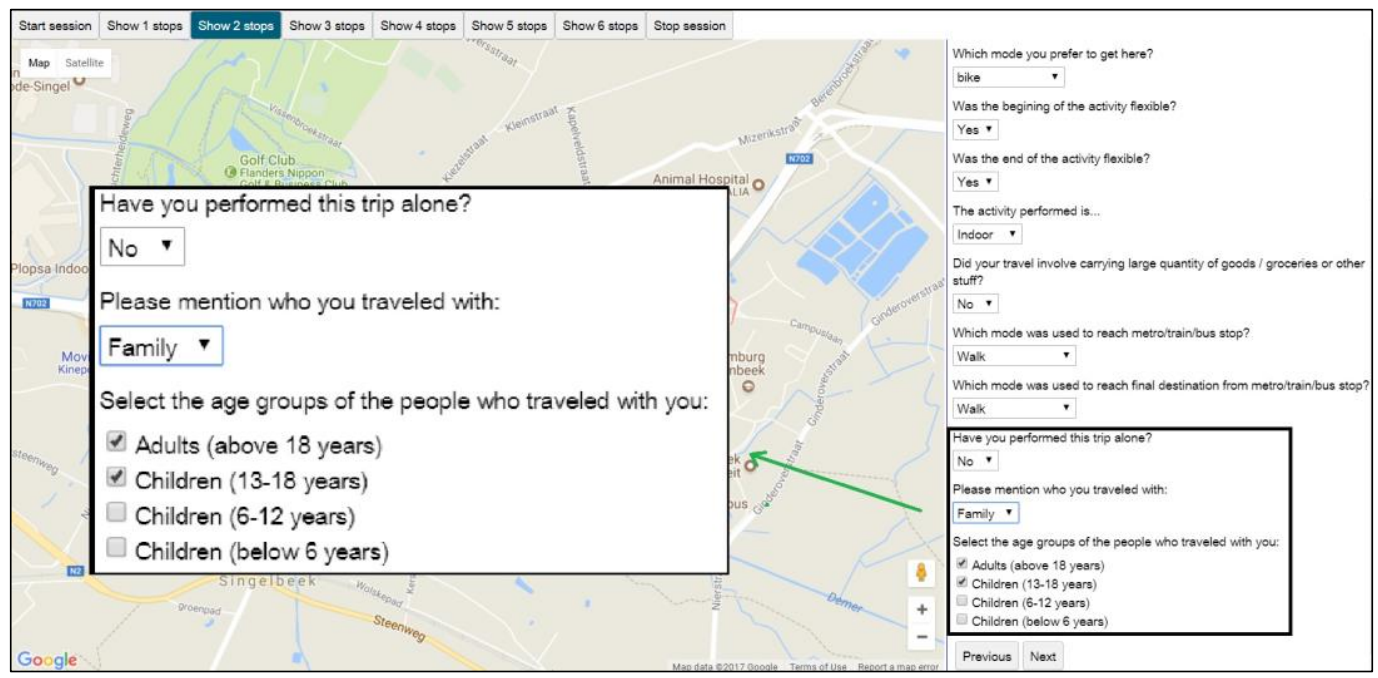

Fig. 3: SPARROWS window showing Questions related to travelling company

\section{Algorithm Development}

The development of an algorithm for the assessment of pro-environmental potential is based on the norm identified in environment psychological literature[3,4]. This norm is based on the idea to identify those aspects of an individual travel behavior from the entire daily activity travel pattern of an individual that can be relatively easy to change. This is because for an informational intervention it is needed to quantify and present the consequences of this soft behavior with and without their replacement with pro-environmental options, so that to encourage the use of such options. The pro-environmental potential in this study is considered based on our earlier discussion, i.e. reduced car use, use of active mobility, reduced participation in non-mandatory outdoor activities and reduced cold start of vehicle engines. 
The first necessary step is to identify threshold limits based on the factors/constraints for mode of travel, cold starts and outdoor non-mandatory activities. These are defined in section 4.1, 4.2 and 4.3.

\subsection{Rules- Travel mode}

Rules were defined on the basis of the norms identified in the literature and some decent considerations about the situational factors regarding mode choice $[28,29,32,33]$. The active mobility is often expressed by a walk, bike and public transport. In order to determine the potential mode shift from car to actives modes of travel, we defined the following rules. General rules required for the initial assessment for potential mode shift from car to active modes is mentioned first while later more mode-specific rules are mentioned.

a) General Rules

- Trip is not part of a complex activity-travel tour, where an individual is using a personal vehicle to travel for other activities within the same tour.

- End time of activity at the origin or start time of the activity at the destination is flexible.

- Not carrying a large quantity of goods and the activity at a destination is not of a pick-up type

b) Potential mode shift from Car to Walk:

- Maximum travelled distance travelled up to $1 \mathrm{~km}$

- Weather conditions are reasonable (no heavy showers/ not very cold (i.e. outdoor air temperature is less than $\left.0{ }^{\circ} \mathrm{C}\right)$ )

- The accompanying persons do not include children (less than 6 years old)

c) Potential mode shift from Car to Bicycle

- Maximum travelled distance travelled up to $3 \mathrm{~km}$

- Segregated bike lanes are available (at least half of the path).

- Age of an individual is between 12 and 60 years.

- Weather conditions are reasonable (no heavy showers/ not very cold (i.e. outdoor air temperature is less than $\left.5^{\circ} \mathrm{C}\right)$ )

- The accompanying persons do not include children (defined as less than 12 years old).

- Other accompanying adults and children can ride a bike and bike is available to all.

- $\quad$ Path gradient is less than $8 \%$.

- Crossings in the bike path are limited to 3 .

d) Potential mode shift from Car to Public Transport (Bus/Train/Tram):

- Availability of public transport between the specific origin and destination.

- Travel time difference between the used mode and public transport is no more than 30 minutes

- Maximum total access/Egress walk up to $1 \mathrm{~km}$

- Waiting time no longer than 10 minutes

- Number of transfers limited to 1 only.

- Weather conditions are reasonable (no heavy showers/ not very cold (i.e. outdoor air temperature less than $\left.0{ }^{\circ} \mathrm{C}\right)$ ).

- Children less than 6 year old are not accompanying.

It is important to note that the above rules are defined for normal and healthy individuals with no significant mobility related disability.

\subsection{Rules- Cold starts of vehicle engine}

Cold starts for car-related trips have been observed to emit significantly higher levels of air pollutants such as CO, HCs and NOx compared to hot starts. It is reported in the literature[25] that trips following a parking lasting 3-8 hours 
contain a cold start. The variation in the parking duration depends on the type of vehicle and engine. For this study, we defined the following rules:

- Cold start is considered if the duration of activity preceding the car trip is more or equal to 4 hours.

- Cold start for the day-starting car trip and return trip after work activity is ignored as the purpose is to curtail excessive cold starts.

- Work-based tours (usually for lunch) and home-based other tours performed by car may contain cold start, which is considered excessive if the following conditions [22,34,35] are met

O One-way trip distance is less than $3 \mathrm{~km}$ (to be replaced with bicycle) and $1 \mathrm{~km}$ (to be replaced with walk)

- Overall in-vehicle travel time difference between the two car trips of the tour and with replaced mode should not be longer than 15 minutes

- Other general conditions for bikeability and walking as described in section 4.1 should also be observed.

- Possibility of reduction of separate home-based car tours by performing more complex car tours (chaining of activities), if the gap between the tours is longer than 4 hours. In such conditions the following condition should be met

$\circ$ Activities that need to be chained are flexible in terms of their start time.

\subsection{Rules- Participation in non-mandatory outdoor activities}

Exposure of individuals to air quality pollutants is higher when individuals perform certain activities in the outdoor environment compared to the performance of the same activities indoor[36]. This information is not readily identifiable from GPS based data, therefore a precise question has been asked from the individual about this in the prompted recall instrument. The rules for identifying replaceable outdoor activities are as follows:

- $\quad$ Leisure, Social and other are considered as non-mandatory activities.

- The above activities are considered if performed in the outdoor environment.

- Only 50\% of such outdoor non-mandatory activities are considered for measuring pro-environmental potential over the minimum number of such activities in an entire week. This minimum number is considered as 5 (i.e. one for each day). So, if an entire week data is gathered for an individual, we determine the total of such activities and then subtract 5 from it. If the output is positive, then $50 \%$ of that number is considered as additional that should be avoided by an individual.

- If the non-mandatory outdoor activities are performed in a simple home-based or Work-based tour, both inward and outward trips are also reduced and counted in pro-environmental potential.

- If the non-mandatory outdoor activity is part of the complex pattern (e.g. making a stop way back to home after work activity), then the trips are not reduced, and is considered as a single long trip without that nonmandatory outdoor activity and route is also considered the same. The duration of next indoor activity is increased the same amount as of the replaced non-mandatory outdoor activity.

\subsection{Integration- Data and Rules}

The next major step for the development of an algorithm is the integration of the different datasets with the help of developed rules in order to assess the final pro-environmental potential. A computer program is written for this purpose, whose final output is in the form of pro-environmental potential. The skeleton of the software is depicted in the Fig. 4. 


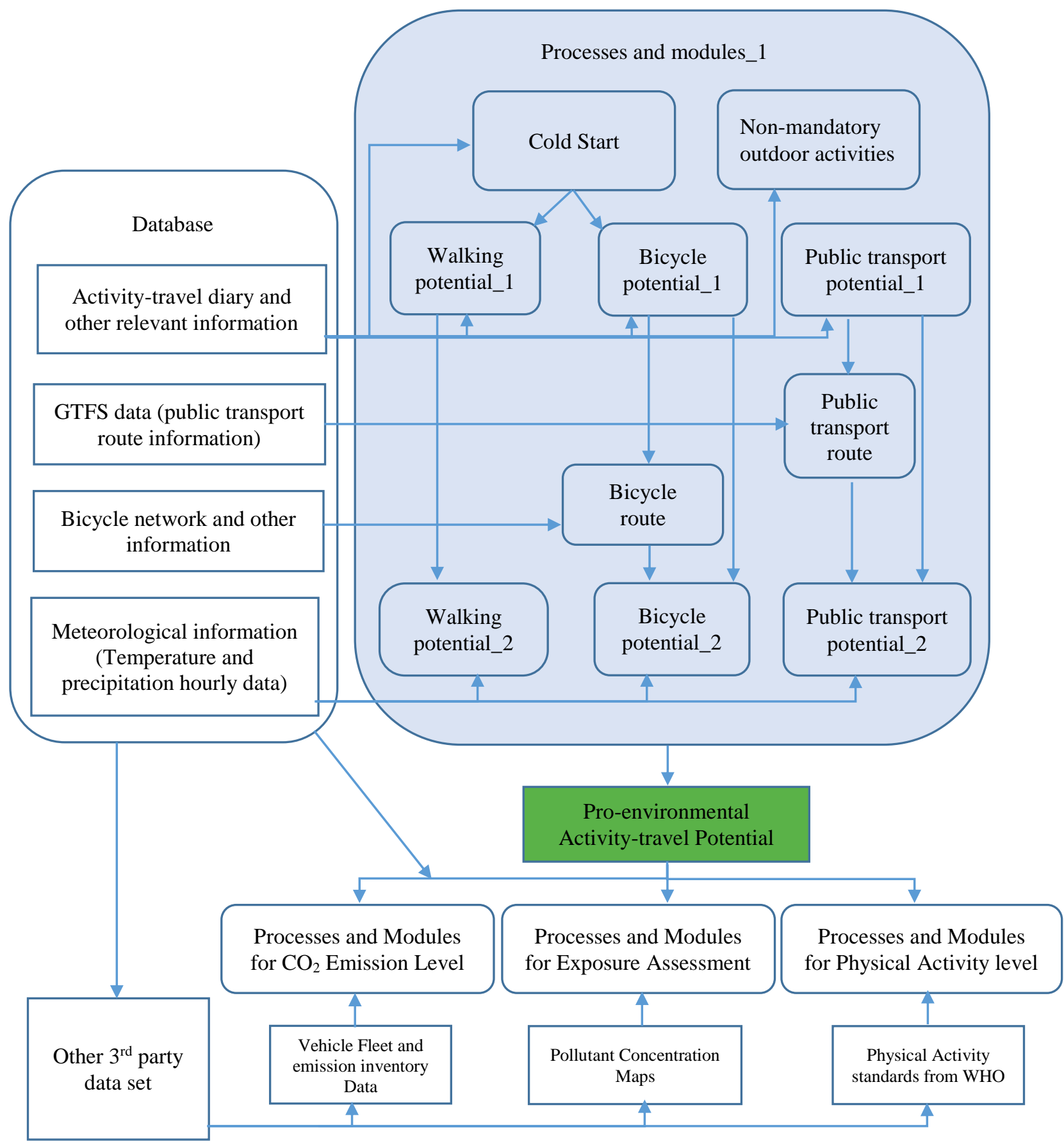

Fig. 4: Skeleton for the assessment of pro-environmental potential and its impacts

The above skeleton developed for the assessment of pro-environmental potential is described here in detail. The initial and crucial task is the setting up of the initial database that is utilized during the development of all the processes and modules. The database has four important datasets that are mainly related to the implementation of rules defined in section 4.1, 4.2 and 4.3. In the first phase, processes related to walking, cycling and public transport potential is initialized by extracting the information stored in the activity-travel diary database and the resulted output is displayed 
as potential_1. So, the walking potential_1 and other similar modules are generated based on the rules associated with individual activity-travel routine such as trip length, activity flexibility, luggage/goods carried and accompanied person details. In the second phase, potential car trips considered for replacing by cycling and public transport are then further examined based on the route characteristics and network information. In this regard, cycling potential_1 is further screened by checking the route feasibility by assessing bicycle network data and meteorological conditions. The final output is generated and stored as cycling potential_2. Similarly, Public Transport potential_1 is further scrutinized by assessing GTFS data using its route module and the last check is applied using meteorological data to get the public transport potential_2. Route module linked with cycling and public transport network data has an ability to identify a most suitable route given an origin and destination as x,y pairs. Each individual trip stored as potential_1 has a starting and ending $\mathrm{x}, \mathrm{y}$ pair which is used as input to get the finalized car trips replaceable potential.

Further, non-mandatory outdoor activity potential is determined by implementing activity module based on rules mentioned in section 4.3 by approaching activity travel diary information. Activity module can separate and store activities that are performed outdoor and attributed as social, leisure and other to get the required potential. Lastly, the replaceable cold starts are determined by initializing the module having a set of rules of section 4.2 that can detect cold starts by tracking activity travel diary information. The cold start potential that requires further examination in terms of walking and cycling needs to go through a similar chain of modules to reach finalized pro-environmental potential. The cumulative pro-environmental potential is considered as suggested activity travel choices used as input for the information-based behavioral intervention.

The measurement of consequences of recorded and suggested individual travel behavior is based on $\mathrm{CO}_{2}$ emissions, exposure to pollutants and physical activity level. $\mathrm{CO}_{2}$ emissions are determined based on the car trips gathered from activity travel diary. Recorded car trips with car information are used to determine emission factors with car fleet information derived from $3^{\text {rd }}$ party dataset to obtain emissions in grams/trip. In a similar manner, emissions for suggested travel behavior is calculated as well to get reduction rate. The following equation, also used in other studies [37], is adopted for the measurement of GHG $\left(\mathrm{CO}_{2}\right)$ emissions.

$$
G H G_{j}=\sum_{i=1}^{N}\left(D_{A i j} \times E F_{A f}\right)
$$

Where

$A$ - Auto, $i$-Trip, $j$ - Individual

$G H G_{j}=$ GHGs for total automobile trips (in $\mathrm{g}$ of $\mathrm{CO}_{2}$ ) for $\mathrm{j}$ individual.

$D_{A i j}=$ Travel distance for automobile on trip $i$.

$E F_{A f}=$ Average emission of $\mathrm{CO}_{2}$ in $\mathrm{g} / \mathrm{km}$ based on the fuel type $f$ of auto $A$ (available for emission inventories).

Individual exposure to pollutants is estimated based on the module that processes individual activity-travel routine data with the help of $3^{\text {rd }}$ party data related to ambient pollutant concentrations. The critical process involved in this module is matching pollutant concentration data with activity-travel data to assess dynamic exposure of a person. This is done by assigning each $\mathrm{x} . \mathrm{y}$ pair of the recorded trip trajectory to the respective $1 \mathrm{x} 1 \mathrm{~km}^{2}$ pollutant concentration zone to get the exposure at that point w.r.t time. Exposure of a trip and activity is calculated by taking summation of the time spent in different pollutant concentration categories (i.e. low, moderate, high and very high) [38]. Furthermore, to account for different micro-environments (i.e. trip performed using different modes or activity is performed indoor/outdoor) we used the available factors in the literature to vary the concentrations accordingly. To explain it further in case of an activity exposure, the spatial location from the recorded data along with the timestamp for each activity is available for each individual. For that particular location and duration of activity at a given time period, changes in the pollutant concentration categories are determined and time spent within each category is noted. The procedure is repeated for all activities individual have performed in a given time period (about one week) and the results are aggregated for the time spent in each category of pollutant concentration. In relation to the trip, each trip is decomposed in several segments on the basis of their association with a particular $1 \mathrm{x} 1 \mathrm{~km}^{2}$ grid of the pollutant concentration data. For the duration of the trip in a given time period, pollutant concentration category belong to that 
grid is assigned. The process is repeated for all segments of the trip, and then, for a particular trip, the time duration spent for each category of the pollutant concentration is determined. The process is repeated for all the trips performed by the individuals in a given time period (about one week). Once the duration distributions for trips and activities are available for each individual, this information is then further aggregated to represent the overall exposure of activitytravel behavior in a given time period.

By considering the replaceable activity travel patterns of an individual, the exposure is recalculated to measure the possible impact. Further, physical activity level is measured with and without pro-environmental potential utilizing the activity travel diary and potentials generated in a respective manner. For analyzing physical activity levels, individual involvement in walking and bicycling for outdoor trips along with the duration of activities which involves exercise/going to gym etc. is considered. To assess the individual involvement in physical activities, we use the threshold limit of 150 minutes per week or 30-minutes of daily limit (for at least five days of the week) as recommended by WHO [39].

Inputs: Trip Activity Data, Bicycle Network Data, Public Transport Network Data, Meteorological data, Vehicle fleet and emission data, Pollutant concentration data, standard Pollutant concentration categories data

Outputs: Pro-Environmental Activity Travel Potentials with consequnces

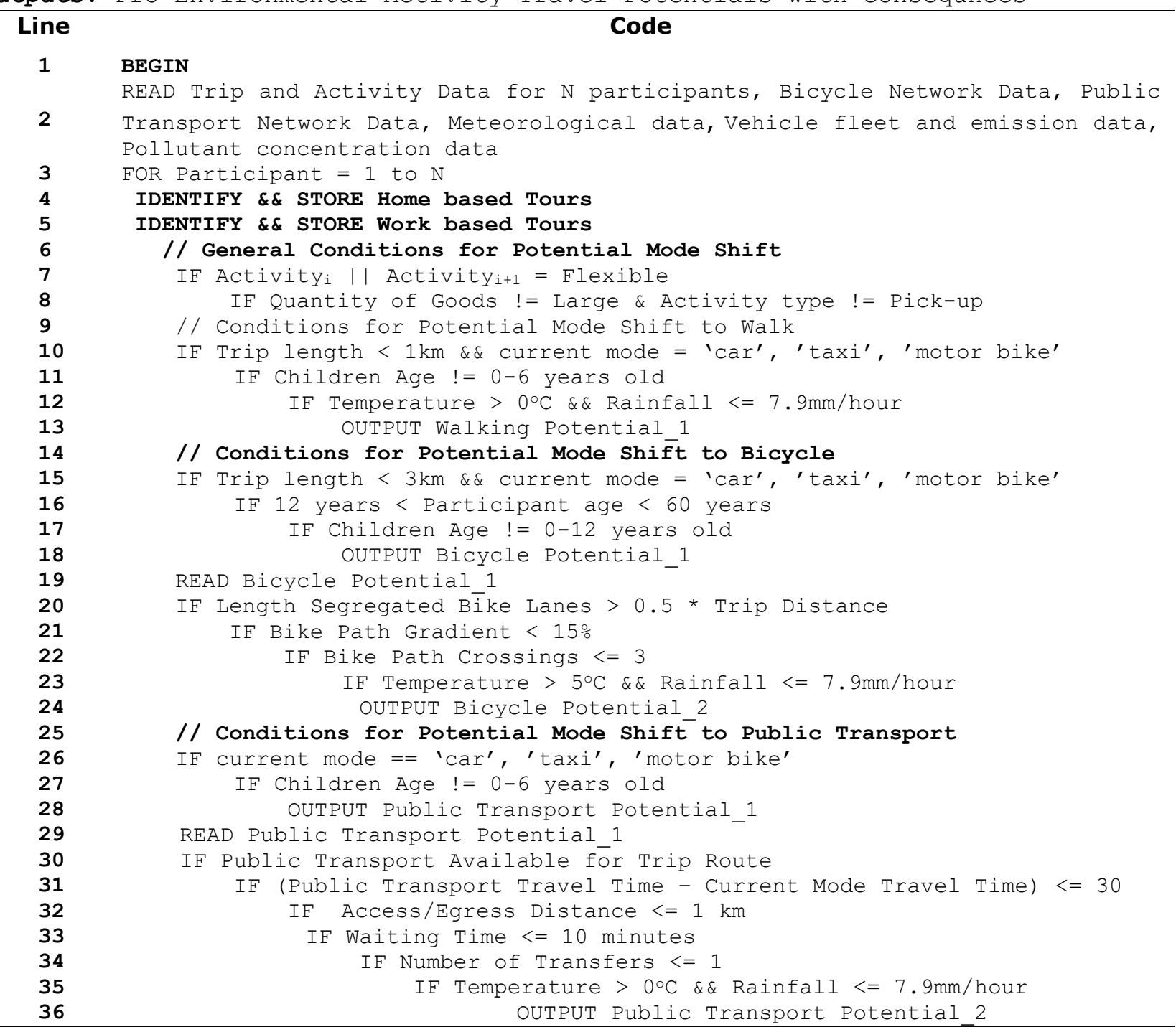


37

// Conditions for Cold Start Detection

IF Tripday $!=1$ \& Tripday $!=\mathrm{n}$ IF current mode $==$ 'car', 'taxi', 'motor bike' $\& \&$ (TripStart $i+1-$ TripEnd $\left._{i}\right)>=4$ hours

OUTPUT Cold Starts Detection

// Conditions for Cold Start Potential

READ Cold Starts Detections

IF Trip length $<1 \mathrm{~km}$

IF (Replaced Mode Travel Time - Current Mode Travel Time) $<=15$ Repeat Conditions for Potential Mode Shift to Walk(Line7-13) OUTPUT Cold Starts Potential

ELSE IF Trip length $<3 \mathrm{~km}$

IF (Replaced Mode Travel Time - Current Mode Travel Time) $<=15$ Repeat Conditions for Potential Mode Shift to Bicycle(Line15-24) OUTPUT Cold Starts Potential

\section{// Conditions for Non-mandatory Outdoor Activities}

IF Activity Type == 'Leisure', 'Social', 'other'

OUTPUT Non-mandatory Activities

IF Activity Performed == 'Outdoor'

OUTPUT Non-mandatory Outdoor Activities

COMPUTE Replaceable Potential=0.5* (Non-mandatory Outdoor Activities - 5)

// Conditions for CO2 Emissions Detection

IF current mode for Trip ${ }_{1-n}==$ 'car', 'taxi', 'motor bike' OUTPUT Trip distance in km for all trips

COMPUTE CO2 Emissions per trip = Trip_distance ${ }_{i}$ * emission factor OUTPUT Total CO2 Emissions

READ Bicycle Potential_2

COMPUTE CO2 Emissions reduction = $\mathrm{CO} 2$ Emissions due to replaceable car to cycle trips

OUTPUT Total CO2 Emissions reduction

// Conditions for Exposure Estimation

CREATE GPS PT DATA (participant id; timestamp, longitude, latitude)

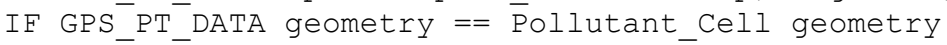

CREATE POLLUTANT_EXPOSURE_DATA (participant_id; timestamp;long; lat; pollutant_cell; pollütant timestamp; Ozone, 02, PM10, PM25)

READ Standard Pollutant concentration categories data COMPUTE time spend by individuali in various pollutant concentration ranges in actual trips \& activities from 1-n COMPUTE time spend by individuali in various pollutant concentration ranges in replaceable trips and activities from $1-n$

// Conditions for Physical Activity Detection

IF current mode for Trip $1-n==$ 'walk', 'cycle' OUTPUT Travel time in minutes for all trips

READ Bicycle Potential_2

COMPUTE Physical activity level increament= Physcial_activity due to replaceable car to cycle trip

OUTPUT Total Physical Activity Level Icreament

Fig. 5: Pseudocode of the developed algorithm

Fig. 5 shows the entire logic of the algorithm in the form of pseudocode used to detect the pro-environmental potentials within the activity travel routine of an individual. Initially, all datasets are assessed based on the various processes involved in algorithm and further based on the activity trip data of each participant specific constraints are applied with the help of various computational logics. At the end, 5 different potentials for each participant are quantified and stored as OUTPUT. Further consequences of activity travel behavior in terms of $\mathrm{CO}_{2}$ emissions, exposure and physical activity level are estimated by utilizing primary datasets and outputs stored in the forms of potentials. 


\section{Case Studies:}

These studies are conducted with the help of Living Labs created under the iSCAPE H2020 Project in six European cities i.e. Bologna, Bottrop, Dublin, Hasselt, Guildford and Vantaa. Therefore, initially with the cooperation of three Living Labs i.e. Hasselt, Bologna and Guildford, citizens were recruited for conducting a pilot study in order to test the working of the developed algorithm. An individual activity travel diary information is collected for one week in all three cities. Based on the collection of other datasets as identified in the methodological framework and algorithm development section the pro-environmental potential is determined. It is important to note that developed computation algorithm is simulating a single individual at a time. The cumulative results obtained are presented and discussed in the following sections.

\subsection{Hasselt City}

Hasselt is one of the urbanized Arrondissement in the Limburg province of Belgium. In the last two decades, car ownership has significantly increased in the area, which raised problems like traffic congestion and air pollution. In Hasselt, 73 percent of the total trips are performed by using a car as compared to Public and active transport [40]. In order to assess the pro-environmental potential, the data related to an individual activity-travel patterns were collected in the month of August 2017 from 25 citizens. Usually, during this part of the year, the temperature ranges between 10 and $22{ }^{\circ} \mathrm{C}$ and there are around $29 \%$ of the chances of a wet day (precipitation of at least 0.04 inches). It was noted that around similar \% of citizens in terms of the 3 age groups i.e. 18-30, 31-44 and greater than 44 years have participated in the study. Majority of participants have education status equivalent to a bachelor's degree or above (i.e. $87 \%$ ) however, income distribution has observed to be more uniform.

Table 1 provides some interesting insights regarding potential in terms of the walk, bicycle and public transport mode by replacing car trips. It should be noted that citizens are not using a car for the trips which are limited to $1 \mathrm{~km}$ or less, while the availability of a car creates a tendency to perform trips of distance greater than $1 \mathrm{~km}$. Furthermore, it is noted that a considerable number of trips are performed in the $1-3 \mathrm{~km}$ range, with a significant potential to be replaced by bicycle. Similarly, car trips can be replaced by public transport. It is interesting to observe that without harder constraints, individuals are involved in choices which are not sustainable. This is often referred in the literature as habitual behavior [41]. These statistics show that there is a significant potential in terms of environmental benefits if individuals are encouraged to change their behavior. Therefore, this potential needs to be exploited. Further, Table 2 also presents the details of actual and replaceable potential of excessive cold starts of a car and individual participation in non-mandatory outdoor activities. It is important to note that non-mandatory outdoor potential is measured as $50 \%$ of the total after subtraction by 5 (as a minimum allowed number of such activities). Again, it can be seen that this potential is significant and its decrease by some percentage, could lead to an improvement of overall air quality.

The consequences of travel behavior associated with Hasselt citizens by considering replaceable potential is computed by utilizing the developed algorithm. In this regard, consequences such as. $\mathrm{CO}_{2}$ emissions and physical activity level for short car trips within $3-\mathrm{km}$ potentially replaceable by cycle are quantified and shown in Table 3 . Around 8 percent reduction in $\mathrm{CO}_{2}$ emissions and 11 percent increase in physical activity level per week for an individual is found by considering the replaceable car trips within $3 \mathrm{~km}$ as compared to the recorded travel routine. Further, the impact in terms of exposure to pollutant with and without pro-environmental potential is estimated for each individual and represented in a cumulative way in Fig. 6a and 6b. It can be seen that during around 74 percent of the total time, individuals are exposed to a low range of pollutant concentration, whose value can be increased up to 80 percent by considering pro-environmental replaceable activity travel alternatives. Further exposure to higher pollutant categories i.e. moderate, high and very high can be reduced by following the suggested mobility patterns. The most surprising aspect of this finding is the possibility to reduce completely the exposure to "Very High" category, with hazardous effects for human health. Hence it can be concluded that a significant amount of environmental as well as personal health benefits can be achieved by adopting the suggested travel choices. 


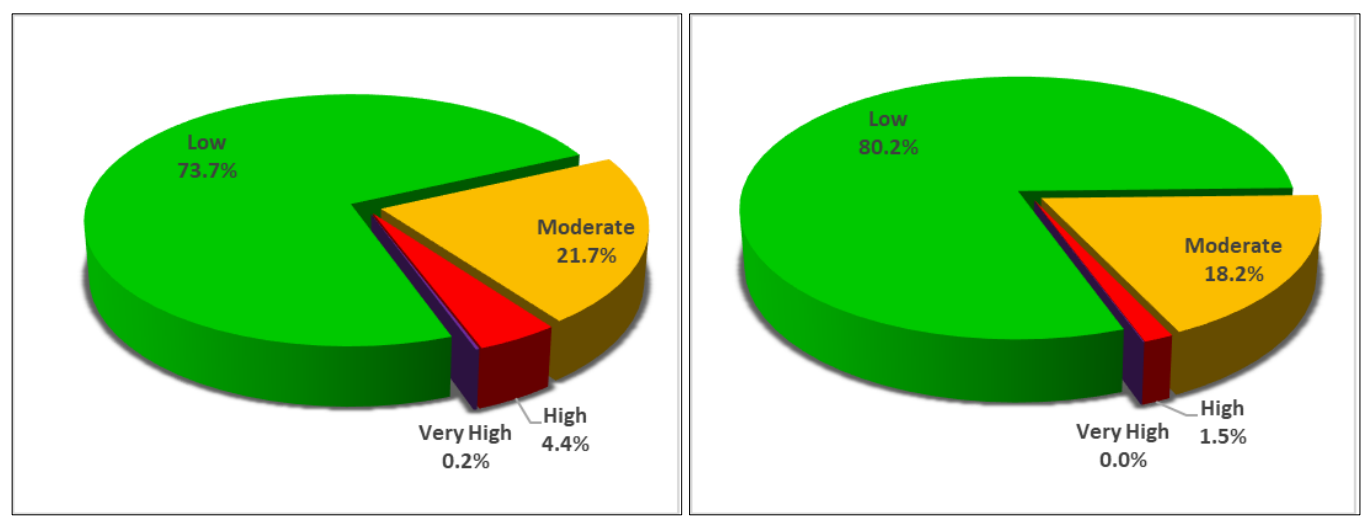

Fig. 6a: Average Hasselt individual exposure based on recorded activity travel patterns

Fig. 6b: Average Hasselt Individual Exposure by considering pro-environmental activity travel alternatives

\subsection{Bologna City}

Bologna is one of the most densely populated cities in Italy and located in the Po Valley, a well-recognized hotspot in terms of air pollution and climate change, defined from the Po river basin and surrounded by mountain. Its unique geographical position makes it an important crossroad for rail and road transportation. It has an international airport that further enhances city characteristic as a transportation hub. It is also known as a university town as Bologna has an old university with around 85,500 students. As a center of education and industry, workforces from surrounding municipalities commute to Bologna [42] and create traffic congestion in the city. For the purpose of assessing proenvironmental potential in an individual activity-travel behavior, 25 Bologna citizens were recruited to record their activity travel routine in the month of November 2017, even though only 18 managed to record their complete diary. The average temperature during this month ranged from 4 to $11{ }^{\circ} \mathrm{C}$ with 26 percent chances of rain on a day (precipitation of at least 0.04 inches) [43]. Of the study group, around $46 \%$ of the subjects have age above 44 years and $39 \%$ between 18-30 years. Almost two-thirds of the participants (62\%) have an education status equivalent to a bachelor's degree or above and $43 \%$ have a yearly income of over 50,000 euros per year.

The output generated by the algorithm is summarized in a tabular form as shown in Table 1. It can be seen that in this case individuals were performing trips within $1 \mathrm{~km}$ by car but the potential to replace them by walk is insignificant. The reason is that most of such trips are linked with complex travel patterns. Significant potential to replace the trips performed within 1- $3 \mathrm{~km}$ by bicycle is also observed. Similarly, a substantial amount of trips can be replaced by public transport as depicted in Table 1. It can be concluded that individuals in the city are involved in not sustainable choices. It is therefore needed to aware and encourage people to adopt environmental friendly travel alternatives. Table 2 shows the details of recorded and replaceable potential of excessive cold starts of a car and also individual involvement in non-mandatory outdoor activities. The result shows that this potential is significant and its decrease of some percentages may bring a positive outcome for improving air quality.

Further, the impact of short trips within $3 \mathrm{~km}$ is also assessed based on the replaceable potential within the activitytravel behavior of an individual. Possible impact in terms of percentage change in $\mathrm{CO}_{2}$ emissions and physical activity level per individual in a week is computed using the developed data-driven computational algorithm. The average reduction in $\mathrm{CO}_{2}$ emissions and increment in physical activity level are found to be 1 and 3 percent respectively as evident from the Table 3. Moreover, Fig. 7a and 7b present the average exposure of Bolognesi citizen to different pollutant concentrations during their recorded and suggested activity travel routine. 75 percent of the recorded activity travel time, individuals were exposed to low range pollutant concentrations which can be further improved to 83 percent by considering pro-environmental mobility options. Consequently, reduction in exposure to higher categories can be achieved as well. It is also interesting to see that the complete reduction of exposure to "Very High" category is possible with hazardous effects for humans. 


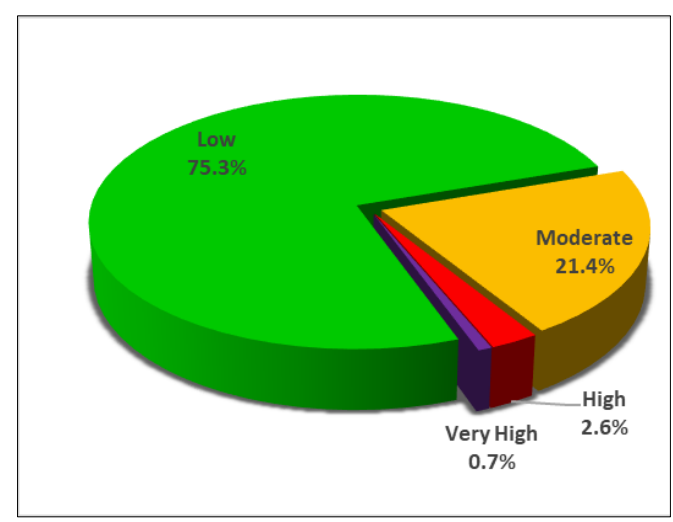

Fig. 7a: Average Bolognesi individual exposure based on recorded activity travel patterns

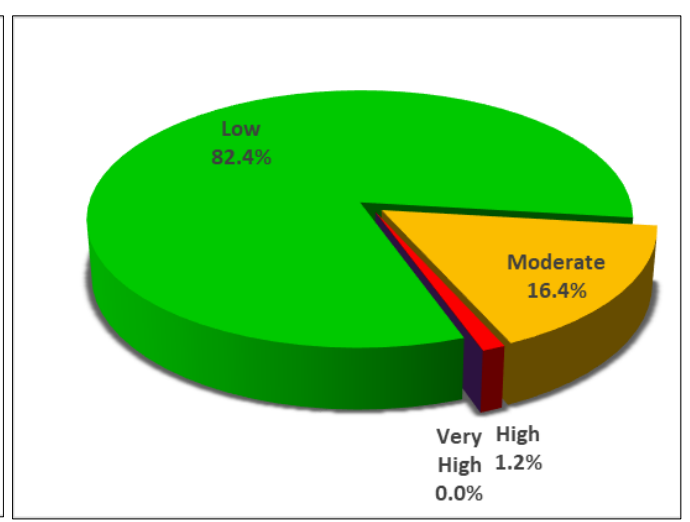

Fig. 7b: Average Bolognesi individual exposure by considering pro-environmental activity travel alternatives

\subsection{Guildford City}

Guildford is located in the vicinity of economically strong capital London (UK), which has an influential role in the labor and education markets. Guildford is the core of a functional urban area itself because it has the oldest university having a large number of students and staff that commute from the nearby municipalities. As Guildford is within commuting distance to London, the city is facing similar type of issues like a capital city such as the rapid increase in population, congested transportation systems etc. With the aim to assess the pro-environmental potential in an individual activity-travel behavior, 25 Guildford residents were recruited in the month of May 2018. Only 13 participants managed to record activity travel diary of complete one week that was further used in the analysis. During this time period, the temperature normally felt in the range of 7 to $18{ }^{\circ} \mathrm{C}$ with 23 percent chances of rain on a day (precipitation of at least 0.04 inches) [44]. In the study, around $56 \%$ of the participants have age above 44 years and $31 \%$ between 31-44 years. Majority of the participants have education status equivalent to a bachelor's degree or above (i.e.88\%) and nearly similar proportion (i.e.86\%) has yearly income above 50,000 pounds.

The results obtained after computations is shown in table 1. Statistics show that there is no significant replaceable potential within short car trips of $1 \mathrm{~km}$. On the contrary, the trips performed within $3 \mathrm{~km}$ by car have a considerable replaceable potential by bike. In addition, substantial trips can be replaced by public transport as illustrated in Table 1.

Table 2 is giving insights about recorded and replaceable potential of excessive cold starts of a car and also individual involvement in non-mandatory outdoor activities. It can be seen that this potential is significant and its reduction of some percentages might lead to an improvement of air quality.

The consequences of recorded travel behavior of Guildford resident was assessed by comparing with the proenvironmental travel choices available. Here we are presenting only the possible impacts of short trips within $3 \mathrm{~km}$ to be potentially replaced with cycling. Table 3 shows that 3 percent $\mathrm{CO}_{2}$ emission reduction and 10 percent increase in physical activity in a week are possible if an individual follows the replaceable cycling alternatives. Based on the statistics, it is not wrong to say that fruitful health and environmental benefits can be achieved by performing the short trips by cycle rather than by car.

Table 1: Participant Car Usage characteristics and its replaceable potential

\begin{tabular}{|c|c|c|c|c|c|c|}
\hline \multirow[b]{2}{*}{ Statistics } & \multicolumn{6}{|c|}{ Car Trips } \\
\hline & $\begin{array}{l}\text { Within } \\
1 \text { km }\end{array}$ & $\begin{array}{l}\text { Walking } \\
\text { potential }\end{array}$ & $\begin{array}{c}\text { Within } \\
3 \text { km }\end{array}$ & $\begin{array}{l}\text { Bicycle } \\
\text { Potential }\end{array}$ & $\begin{array}{l}\text { Total } \\
\text { trips }\end{array}$ & $\begin{array}{c}\text { Public } \\
\text { Transportation } \\
\text { Potential }\end{array}$ \\
\hline
\end{tabular}




\begin{tabular}{lcccccc}
\hline & \multicolumn{7}{c}{ Hasselt } \\
\hline Sum $(\mathrm{N}=25)$ & 0 & 0 & 82 & 23 & 192 & 42 \\
\hline Mean & 0 & 0 & 3.28 & 0.92 & 7.68 & 1.68 \\
\hline Sum $(\mathrm{N}=18)$ & 23 & 4 & 73 & 10 & 211 & 79 \\
\hline Mean & 1.28 & 0.22 & 4.06 & 0.56 & 11.72 & 4.39 \\
\hline \multicolumn{7}{c}{ Guildford } \\
\hline Sum $(\mathrm{N}=13)$ & 21 & 1 & 62 & 16 & 202 & 57 \\
\hline Mean & 1.62 & 0.08 & 4.77 & 1.23 & 15.54 & 4.38 \\
\hline
\end{tabular}

Table 2: Cold start and non-mandatory outdoor activities and its replaceable potential

\begin{tabular}{|c|c|c|c|c|}
\hline Statistics & Cold Starts & $\begin{array}{l}\text { Cold Starts } \\
\text { Potential }\end{array}$ & $\begin{array}{l}\text { Non-mandatory } \\
\text { outdoor Activities }\end{array}$ & $\begin{array}{c}\text { Non-mandatory outdoor } \\
\text { Activity Potential }\end{array}$ \\
\hline \multicolumn{5}{|c|}{ Hasselt } \\
\hline Sum $(N=25)$ & 115 & 39 & 52 & 18 \\
\hline Mean & 4.61 & 1.56 & 2.08 & 0.72 \\
\hline \multicolumn{5}{|c|}{ Bologna } \\
\hline Sum $(\mathrm{N}=18)$ & 95 & 40 & 92 & 22 \\
\hline Mean & 5.28 & 2.22 & 5.11 & 1.22 \\
\hline \multicolumn{5}{|c|}{ Guildford } \\
\hline $\operatorname{Sum}(\mathrm{N}=13)$ & 102 & 35 & 78 & 14 \\
\hline Mean & 7.85 & 2.70 & 06 & 1.07 \\
\hline
\end{tabular}

Table 3: Consequences of Replaceable car trips with in $3 \mathrm{~km}$ to cycling in a week per person

\begin{tabular}{ccc}
\hline City & $\begin{array}{c}\mathrm{CO}_{2} \text { Emissions } \\
\text { Reduction (\%) }\end{array}$ & $\begin{array}{c}\text { Physical Activity } \\
\text { Level Improvement (\%) }\end{array}$ \\
\hline Hasselt & 8.01 & 10.65 \\
\hline Bologna & 1.00 & 3.01 \\
\hline Guildford & 2.77 & 9.85 \\
\hline
\end{tabular}

\subsection{Discussion}

This study is initialized with the need to identify constraints/factors associated with the individual activity- travel behavior to adopt pro-environmental travel choices. An effort is made to identify all possible factors and constraints with the help of available literature related to travel behavior and environment psychology. Constraints related to personal, household, mobility, urban environment and meteorological conditions is found to be effective in determining realistic pro-environmental potential within activity travel routine of an individual. Based on the identified constraints and limitations, certain rules based on common practices are devised for developing an algorithm to assess the potential mode shift from car to walking, cycling and public transport. So far, no similar investigations were found in which replaceable potential was assessed in such a holistic and comprehensive manner. Furthermore, consequences of potential changes are quantified at the individual level in terms of $\mathrm{CO}_{2}$ emissions and physical activity level, which were not determined before by adopting such a rigorous approach.

Based on the output generated from the developed algorithm, it can be clearly seen from Table 1 and 2 that citizens of the three cities i.e. Hasselt, Bologna and Guildford have different travel behavior and replaceable potential in terms of car trips, cold starts and non-mandatory outdoor activities. As can be observed from Table 1, Hasselt individuals are not involved in car trips of less than $1 \mathrm{~km}$ as opposed to Bologna and Guildford citizens. This observation can be due to the fact that in Hasselt facilities are located quite far away or because citizens owning a car tend to travel more to reach a facility. The average recorded trips per person within $3 \mathrm{~km}$ and its replaceable potential were found to be 
highest for Guildford ( 5 and 1 percent, respectively). As the city is very close to an economic hub, most of the people use their personal cars to commute to London on a daily basis which makes them habitual car users. Furthermore, it is apparent from Table 1 that 38 percent of the replaceable potential per individual is available in terms of public transport in Bologna. The preference of car as the effective mode of transportation is probably due to the slow bus system and poor infrastructure related to the active mode of travel in Bologna [45].

Table 3 summarizes the possible impact of detected replaceable potential for less than $3 \mathrm{~km}$ car trips. The weekly reduction in $\mathrm{CO}_{2}$ emissions was found to be around 8, 1 , and 3 percent for Hasselt, Bologna and Guildford residents respectively. It is important to note that the above-mentioned reduction in $\mathrm{CO}_{2}$ emissions is possible just considering replaceable trips within $3 \mathrm{~km}$, a behavior which is easy to adopt. In addition, significant health benefits in terms of improvement in physical activity level can be achieved i.e. 11,3 and 10 percent due to potential mode shift from car to cycle for trips within $3 \mathrm{~km}$. These findings play a major role in the development of an effective informational based behavioral interventions.

Furthermore, the present study presents also a few limitations. In order to collect individual activity travel patterns, a GPS based smartphone application SPARROWS was used, which is proved to be a good tool except for some technological issues prevalent in GPS data. Occasionally, due to bad GPS signals, the exact location or trajectory was not recorded which potentially lead to misrepresentation in an individual activity-travel diary. Further, due to the battery drainage of the cell phone, interruptions in the recording of activity trip patterns were also observed. Additionally, while assessing replaceable potential, meteorological conditions were considered for the time period in which activity travel data was recorded. However, this study did not consider the change of meteorological conditions during the course of the year, that can affect the potential, which is an overall limitation. Wind conditions are also not taken into account which can influence the calculated potentials. The effect of wind conditions should be considered in the future studies. In relation to exposure determination, previous studies have used high quality resolution data of pollutant concentration. Due to the non-availability of such data, here we have used pollutant concentration maps of $1 \mathrm{x} 1 \mathrm{~km}^{2}$. However, the developed algorithm has the adaptability to work well with low resolution maps to give a much accurate estimation of exposure.

\section{Conclusion}

In this paper, an algorithm attempting to determine the pro-environmental potential in an individual activity-travel behavior is presented. The developed algorithm considers a variety of constraints and factors associated with individual travel decisions which are identified in the literature. The pro-environmental potential with associated consequences determined from the algorithm has a significance in designing an informational intervention, where information presented to the user is customized, and provides a clear justification about the advantages these changes will bring in terms of increase in physical activity level and reduction of their contribution in $\mathrm{CO}_{2}$ emissions. The algorithm utilizes state-of-the-art data collection methodologies which provide essential details of an activity-travel routine of individuals such as GPS based smartphone application and prompted recall survey. The developed algorithm is tested for the data collected from Hasselt, Bologna and Guildford citizens and the results reported from such an algorithm are encouraging.

\section{Acknowledgements}

This project has received funding from the European Union Horizon 2020 research and innovation programme under grant agreement No 689954. This paper reflects the authors views. The European Commission is not liable for any use that may be made of the information contained therein.

\section{References}

1. EEA (2016) Air quality in Europe - 2016 report, Report No. 28. European Environmental Agency. doi:10.2800/413142

2. Steg L, Vlek C (2009) Encouraging pro-environmental behavior: An integrative review and research agenda. Journal of Environmental Psychology 29 (3):309-317. doi:10.1016/j.jenvp.2008.10.004

3. Osbaldiston R, Schott JP (2012) Environmental sustainability and behavioral science: Meta-analysis of proenvironmental behavior experiments. Environment and Behavior 44 (2):257-299 
4. Schultz PW (2014) Strategies for Promoting Proenvironmental Behavior. European Psychologist 19 (2):107-117. doi:10.1027/10169040/a000163

5. Eriksson L, Forward SE (2011) Is the intention to travel in a pro-environmental manner and the intention to use the car determined by different factors? Transportation Research Part D: Transport and Environment 16 (5):372-376. doi:10.1016/j.trd.2011.02.003

6. de Nazelle A, Morton BJ, Jerrett M, Crawford-Brown D (2010) Short trips: An opportunity for reducing mobile-source emissions?

Transportation Research Part D: Transport and Environment 15 (8):451-457. doi:10.1016/j.trd.2010.04.012

7. Kim S, Ulfarsson GF (2008) Curbing automobile use for sustainable transportation: analysis of mode choice on short home-based trips. Transportation 35 (6):723-737. doi:10.1007/s11116-008-9177-5

8. Schmidt K (2016) Explaining and promoting household food waste-prevention by an environmental psychological based intervention study. Resources, Conservation and Recycling 111:53-66. doi:10.1016/j.resconrec.2016.04.006

9. Lieberoth A, Holm Jensen N, Bredahl T (2018) Selective psychological effects of nudging, gamification and rational information in converting commuters from cars to buses: A controlled field experiment. Transportation Research Part F: Traffic Psychology and Behavior 55:246-261. doi:10.1016/j.trf.2018.02.016

10. Möser G, Bamberg S (2008) The effectiveness of soft transport policy measures: A critical assessment and meta-analysis of empirical evidence. Journal of Environmental Psychology 28 (1):10-26. doi:10.1016/j.jenvp.2007.09.001

11. Bamberg S, Fujii S, Friman M, Gärling T (2011) Behavior theory and soft transport policy measures. Transport Policy 18 (1):228-235. doi:10.1016/j.tranpol.2010.08.006

12. Chatterjee K, Bonsall P (2009) Special Issue on Evaluation of programmes promoting voluntary change in travel behavior. Transport Policy 16 (6):279-280. doi:10.1016/j.tranpol.2009.10.001

13. Mikiki F, Papaioannou P (2012) Investigating pro-Environmental and Active Travel Behavior for Successful Sustainable Travel Promotion. Procedia - Social and Behavioral Sciences 48:1424-1433. doi:10.1016/j.sbspro.2012.06.1118

14. Stopher PR, Bullock P (2003) Travel Behavior Modification: A Critical Appraisal. Paper presented at the 26th Australasian Transport Research Forum, Wellington, New Zealand,

15. Scheepers CE, Wendel-Vos GCW, den Broeder JM, van Kempen EEMM, van Wesemael PJV, Schuit AJ (2014) Shifting from car to active transport: A systematic review of the effectiveness of interventions. Transportation Research Part A: Policy and Practice 70:264-280. doi:10.1016/j.tra.2014.10.015

16. Arroyo R, Ruiz T, Casquero D, Mars L (2018) Trip Characteristics Analysis of the Effects of a Travel Behavior Change Program. Transportation Research Record: Journal of the Transportation Research Board. doi:10.1177/0361198118773184

17. Brog W, Schadler M Marketing in Public Transport Is an Investment, Not a Cost. . In: 22nd Australian Transport Research Forum, Sydney, 1998.

18. Rose G, Ampt E (2001) Travel blending: an Australian travel awareness initiative. Transportation Research Part D: Transport and Environment 6:95-110

19. Cairns S, Sloman L, Newson C, Anable J, Kirkbride A, Goodwin P (2008) Smarter Choices: Assessing the Potential to Achieve Traffic Reduction Using 'Soft Measures'. Transport Reviews 28 (5):593-618. doi:10.1080/01441640801892504

20. Fujii S, Taniguchi A (2006) Determinants of the effectiveness of travel feedback programs - a review of communicative mobility management measures for changing travel behavior in Japan. Transport Policy 13 (5):339-348. doi:10.1016/j.tranpol.2005.12.007

21. Zhao F, Pereira FC, Ball R, Kim Y, Han Y, Zegras C, Ben-Akiva M (2015) Exploratory analysis of a smartphone-based travel survey in Singapore. Transportation Research Record: Journal of the Transportation Research Board 2 (2494):45-56

22. Beckx C, Broekx S, Degraeuwe B, Beusen B, Int Panis L (2013) Limits to active transport substitution of short car trips. Transportation Research Part D: Transport and Environment 22:10-13. doi:10.1016/j.trd.2013.03.001

23. James B, Brog W (1999) Potential for Increasing Public Transport, Cycling and Walking Trips. Paper presented at the 23rd Australian Transport Research Forum, Perth, Western Australia,

24. ALR (2016) Moving Toward Active Transportation: How Policies Can Encourage Walking and Bicycling. Active Living Research 25. Martin Weiss, Elena Paffumi, Michaël Clairotte, Yannis Drossinos, Theodoros Vlachos, Pierre Bonnel, Giechaskiel B (2017) Including coldstart emissions in the Real-Driving Emissions (RDE) test procedure: An assessment of cold-start frequencies and emission effects. Joint Research Center Science for Policy Report. JRC Science Hub, Luxembourg: Publications Office of the European Union. doi:doi:10.2760/70237

26. Bielaczyc P, Merkisz J, Pielecha J (2001) Investigation of Exhaust Emissions from DI Diesel Engine During Cold and Warm Start. Paper presented at the SAE 2001 World Congress, Detroit, Michigan, March 5-8, 2001

27. Schoenau M, Müller M (2017) What affects our urban travel behavior? A GPS-based evaluation of internal and external determinants of sustainable mobility in Stuttgart (Germany). Transportation Research Part F: Traffic Psychology and Behavior 48:61-73.

doi:10.1016/j.trf.2017.05.004

28. Saneinejad S, Roorda MJ, Kennedy C (2012) Modelling the impact of weather conditions on active transportation travel behavior.

Transportation Research Part D: Transport and Environment 17 (2):129-137. doi:10.1016/j.trd.2011.09.005

29. Sugiyama T (2018) Cycling: Increasing diversity in users, contexts and modalities. Journal of Transport \& Health.

doi:10.1016/j.jth.2018.08.008

30. Beckx C, Denys T (2016) Analysis of Total belgian car Fleet 2015. Flemish Institute for Technological Research,

31. Kaur S, Nieuwenhuijsen MJ, Colvile RN (2007) Fine particulate matter and carbon monoxide exposure concentrations in urban street transport microenvironments. Atmospheric Environment 41 (23):4781-4810. doi:10.1016/j.atmosenv.2007.02.002

32. Richter J, Friman M, Gärling T (2011) Soft transport policy measures: Gaps in knowledge. International journal of sustainable transportation 5 (4):199-215

33. Pucher J, Dill J, Handy S (2010) Infrastructure, programs, and policies to increase bicycling: an international review. Preventive medicine 50:S106-S125

34. Cole R, Turrell G, Koohsari MJ, Owen N, Sugiyama T (2017) Prevalence and correlates of walkable short car trips: A cross-sectional multilevel analysis. Journal of Transport \& Health 4:73-80. doi:10.1016/j.jth.2016.11.007

35. Lee J, He SY, Sohn DW (2017) Potential of converting short car trips to active trips: The role of the built environment in tour-based travel. Journal of Transport \& Health 7:134-148. doi:10.1016/j.jth.2017.08.008 
36. Gerharz LE, Krüger A, Klemm O (2009) Applying indoor and outdoor modeling techniques to estimate individual exposure to PM2. 5 from personal GPS profiles and diaries: a pilot study. Science of the total environment 407 (18):5184-5193

37. Zahabi SAH, Chang A, Miranda-Moreno LF, Patterson Z (2016) Exploring the link between the neighborhood typologies, bicycle infrastructure and commuting cycling over time and the potential impact on commuter GHG emissions. Transportation Research Part D: Transport and Environment 47:89-103. doi:10.1016/j.trd.2016.05.008

38. Daily Air Quality Index. (2017) Department for Environment Food \& Rural Affairs, UK. https://uk-air.defra.gov.uk. Accessed 5th of June 2017

39. Organization WH (2010) Global recommendations on physical activity for health. World Health Organization,

40. Barrett L, Galik G, Hristova D, Cowie P, Caro F (2017) Challenges and Opportunities in the iSCAPE Cities.

41. Graham-Rowe E, Skippon S, Gardner B, Abraham C (2011) Can we reduce car use and, if so, how? A review of available evidence. Transportation Research Part A: Policy and Practice 45 (5):401-418. doi:10.1016/j.tra.2011.02.001

42. Functional urban areas in OCED countries: Italy. (2016). www.oecd.org. Accessed 14th of June 2018

43. Average Weather in November in Bologna. https://weatherspark.com. Accessed 7th of August 2018

44. Guildford Climate. https://www.metoffice.gov.uk/public/weather/climate/gcpe7p302. Accessed 7th of August 2018

45. Mägdefrau N, Staufenbiel J, Schmitt HC, Gollmann C, Weißer B, Hurth F, Kirstein M, Kumar P, Greiving S (2017) Report on solutions at urban level. 